\title{
Influence of Socio-Demographic Factors on SRAVEN Performance
}

\author{
Raegan Murphy \\ University College Cork, Ireland \\ Nafisa Cassimjee \\ University of Pretoria, South Africa \\ Clare Schur \\ University of Pretoria, South Africa
}

Address corresponding to Raegan Murphy, University College Cork, Applied Psychology, Cork Enterprise Centre, North Mall, Cork, Ireland. E-mail: raegan.murphy@ucc.ie

This exploratory study aimed to investigate the influence of specific socio-demographic variables on a computerized test of non-verbal neuropsychological performance. Six hundred and thirty South African first year students were assessed using the University of Pennsylvania Computerized Neuropsychological Test Battery (PennCNP). Fluid intelligence was measured by a computerized version of the Raven's Progressive Matrices (SRAVENS). Analysis of variance indicated that gender, home language, quality of schooling, language of schooling and paternal education influenced performance on the SRAVEN. Stepwise multiple regression evidenced the importance of language, paternal education and high school language on SRAVENS responses. The assumption of non-verbal test scores as being independent of socio-demographic factors needs to be revisited as such independence cannot be maintained in light of such evidence.

Keywords: non-verbal tests, neuropsychological performance, SRAVENS, socio-demographic factors, culture-dependence

Non-verbal neuropsychological tests have been considered to be relatively culture independent tests (Sherwood, 2005), however current international research indicates that performance on non-verbal neuropsychological tests are significantly influenced by various socio-demographic factors (Ardila \& Keating, 2007; Coffey, Marmol, Schock, \& Adams, 2005; Dotson, Kitner-Triolo, Evans, \& Zonderman, 2008; Dugbartey, Townes, \& Mahurin, 2000; Lynn, Backhoff, \& Contreras, 2005; Mok, Tsang, Lee, \& Llorente, 2008; Razani, Burciaga, Madore, \& Wong, 2007; Rosselli \& Ardila, 2003; Shuttleworth-Edwards, Kemp, Rust, Muirhead, Hartman, \& Radloff, 2004b; Sugarman, 2007). Performance on them may be influenced by language and parental education.

\section{Language and Parental Education}

Razani et al. (2007) examined differences between English speaking ethnically diverse individuals and monolingual English speaking Anglo-Americans and found that the latter group scored significantly poorer on neuropsychological measures when compared to the former group. Noble, Norman, and Farah (2005) found that language ability significantly mediated the correlation between executive performance and aspects of socio-economic status such as parental education. Parents with better education may provide a more stimulating environment, more sophisticated verbal interaction, enhance contextual factors conducive to educational performance and influence the nature and quality of components of executive development (Braga, 2007; Hoff, 2003; Noble, McCandliss, \& Farah, 2007).

Language is integrated with elements of education and proficiency in English (reading and speech ability), specifically better quality education (Nelson \& Pontón, 2007;
Shuttleworth-Edwards, Donnelly, Reid, \& Radloff, 2004a). Quality and type of schooling as external socio-demographic environmental factors and parental education levels as an internal socio-demographic environmental factor have been found to influence cognitive performance (Ardila, Rosselli, Matute, \& Guajardo, 2005; Dotson et al., 2008; Shuttleworth-Edwards et al., 2004a; Shuttleworth-Edwards et al., 2004b). Lynn et al. (2005) investigated Raven Standard Progressive Matrices (RSPM) performance on a multi-ethnic sample in Mexico and reported significant correlations between mother's education level and scores on the RSPM. The authors considered this association as an indication of a complex interaction between socio-demographic factors and performance on an intelligence measure. An alternative explanation is that more intelligent mothers avail themselves of educational opportunities.

\section{Raven's Standard Progressive Matrices Within Diverse Context}

The RSPM is considered to be one of the purest measures of general intellectual ability (Raven, Raven, \& Court, 2000). The test is considered a culture fair measure of non-verbal intelligence (Grieve \& Viljoen, 2000; Rushton, Skuy, \& Fridjhon, 2002). However, factor-analytic studies have indicated that the RSPM may not be a pure measure of general intellectual functioning and that factors inherent in different environments are of particular importance (Raven, Raven, \& Court, 2000). Studies utiliszing the RSPM have been conducted on school and university students from different ethnic groups in South Africa (Grieve \& Viljoen, 2000; Knoetze, Bass, \& Steele, 2005; Owen, 1992; Rushton \& Skuy, 2000; Rushton et al., 2002). 
On a sample of first year university students, Rushton and Skuy (2000) found performance differences between racially categorizsed groups. Differences in neuropsychological performance within the racially categorized groups may reflect conditions inherent in disadvantaged communities such as poor schooling, impoverished environments and low levels of parental education (Griesel \& Richter, 1987; Grieve \& Viljoen, 2000; Nell, 2000).

Shuttleworth-Jordan (1996) emphasized the powerful acculturative processes that would parallel progress in South Africa and mediate socio-demographic influences (language proficiency, parental education, quality of education and medium of education) on cognitive test performance. This study focuses on the dynamic socio-demographic factors most likely to be pervasive in a changing environment such as South Africa.

The case for the independence from socio-demographic variables of certain non-verbal intelligence and neuropsychological tests cannot rest due to the increasing evidence attesting to the significant influence of multiple socio-demographic variables on these performance batteries (Coffey et al., 2005; Mok et al., 2008; Shuttleworth-Edwards et al., 2004b). In order to better serve and more equitably assess candidates on non-verbal performance assessment tools, researchers not only have to be mindful of the consequences of the moderating effects of these variables but need to possibly adjust assessment strategies in order to more accurately assess neuropsychological performance. However, this would depend on the purpose of the assessment exercise. For instance, if the purpose is to compare individuals from different home language groups as they present themselves, then adjustment may not be required and may falsify the data. If the purpose is to check what a candidate is capable of learning, then adjustment has to be made if it is believed that neuropsychological measures can predict ability to improve by learning.

Group differences abound in South Africa, not so much due to inherent demographic factors but more so due to past contextual differences, which resulted in varying quality of education and access to facilities. The South African sample's performance on the SRAVEN is on a par with that of the norm sample as evidenced by Penn normative data (the mean correct responses on SRAVEN in our sample was 42.7 which was slightly higher than the norm group mean of 41.41). However, upon closer inspection differences on test performance arise due to language use, school language during primary and high school as well as father's education. These socio-demographic factors are directly linked to past social inequities and do bias performance on tests of non-verbal intelligence. It cannot conclusively be shown that without the social inequities there are no differences.

\section{Goals of the Study}

Considering that the RSPM is classified as a culture-fair test of non-verbal cognitive ability (Raven, Court \& Raven, 1990) the present study aimed to investigate socio-demographic influences on a computerized version of RSPM performance in a diverse South African university sample. To date, few studies in South Africa have included large samples, a computerized test medium, a differentiation of parental education, and differentiation of language of schooling and quality of primary and secondary education. A number of preliminary research questions were addressed. The performance on the SRAVEN was investigated along with any gender effects. Various socio-demographic factors such as home language, quality of schooling, language of schooling and parental education were investigated for possible influence on the performance on the SRAVEN. Possible interaction effects were also investigated. The variable impact of socio-demographic factors was investigated in order to build a preliminary predictive model on SRAVEN's performance.

\section{Method}

\section{Participants}

Six hundred and thirty first year students at a large residential university in South Africa participated in this study in return for credits in a psychology semester module. Thirty three cases were deleted due to incomplete records and questionable data. A realized sample of 597 was utilized for the final data analyzes. Sixty-one percent of the sample had fathers who had progressed beyond the level of high school education, and $66 \%$ of the sample had mothers with the same progression.

At home, $28 \%$ of the sample spoke English, $47 \%$ spoke Afrikaans and the remaining $25 \%$ spoke a black language. It must be noted that home language and language of schooling is not always the same. Primary and high school education was received in either English or Afrikaans.

Traditionally, quality of schooling is deemed better in privately funded schools as opposed to the quality of education received in state and semi-state subsidized schools in South Africa (Maree, Aldous, Hatting, Swanepoel, \& van der Linde, 2006). Quality of schooling for this study was operationalised as either state subsidized or privately funded. Forty-seven percent of the sample attended private schools and 53\% received state-funded schooling during their primary school phase. The trend was reversed for high school attendance, with $53 \%$ attending private schools and $47 \%$ attending state-subsidized schools.

\section{Measures}

The University of Pennsylvania Computerized Neuropsychological Test Battery (PennCNP) was used for this study. The full battery of the PennCNP comprises the Emotions battery, Executive Functioning and Abstract Reasoning battery and the Memory battery. The computerized SRAVEN is a short version of the standard pencil and paper RSPM. It comprises 9 questions from the standard 60 RSPM, which has 60 questions. The 9 questions were chosen based on statistical analyzes of the RSPM, which demonstrated that the selected questions could predict the scores of the standard 60 question RSPM. In a study of 92 healthy individuals, Gur et al. (2001) reported a mean performance of $47(S D=6.6)$ and a high reliability $(0.88)$ on the computerized version of the RSPM.

A self completion questionnaire was designed to capture basic data about respondents' gender, age, handedness, language of schooling (primary and high), home language, quality of education (primary and high) and parental education levels.

\section{Procedure}

The choice of a computerized battery facilitated large scale data collection and group administration (Gur et al., 2001). Working in collaboration with the Brain-Behavior Laboratory at the University of Pennsylvania, the researchers were able to set up a web-interface between the South African site and the USA site. The computer laboratory at the University of Pretoria was used for the group administration of tests. Participants were required to choose a scheduled session and were assigned to 
groups. In total 30 group sessions were scheduled. Each group comprised a maximum of 25 participants. In addition to three attending researchers, eight research assistants were trained in the administration of the battery. Each research assistant was responsible for the simultaneous monitoring of 4 participants. The research assistants had to electronically submit, upon completion of each task, the test status code (C-complete, I-incomplete) and the number 1 (good data), 2 (questionable data) or 3 (bad data) at the end of the testing session.

A measure of sensory-motor ability (MPRAXIS) was administered before the tests commenced so as to allow participants to familiarize themselves with the use of the computer mouse and the computer-based testing procedure. Prior to the commencement of the SRAVEN test session, participants were given a practice trial to ensure that they were familiar with the requirements of the test. Performance indices for the SRAVEN were determined as follows: a) Total correct responses b) Total reaction time for correct responses, c) Total reaction time for error responses.

\section{Data Analysis}

The functioning of the SRAVEN was addressed by analyzing various descriptive indicators such as percentiles, means and standard deviations and comparing these to available normative samples. Gender effects were addressed by analyzing differences for the two groups and, to this end, a non-parametric test was used due to unequal sample distribution. Analysis of variance and tests of difference, including post-hoc tests of difference, were employed to determine the possible influence of various socio-demographic factors on the performance of the SRAVEN. A general linear univariate model was tested in order to address possible interaction effects. Lastly, stepwise multiple regression was employed to investigate the variable impact of socio-demographic factors on SRAVEN's performance.

\section{Results}

\section{Descriptive Analysis}

Table 1 illustrates the psychometric data for performance on the SRAVEN. The sample achieved a mean of $42.7(\mathrm{SD}=9.8)$ out of a total of 60 . Table 2 gives further descriptive data for the SRAVEN with the Penn norm sample results added for comparison. The Penn normative sample $(n=117)$ is more heterogeneous in terms of age and has more males than females resulting in more variance in the range of scores. The samples are similar in terms of scores within the percentiles, with lower norm sample scores on the 25th percentile. The distribution of scores were skewed to the right indicating a possible ceiling effect for all groups. The SRAVEN functioned normally for this multi-ethnic sample.

\section{Gender Effects}

A t-test for independent groups was performed to investigate differences in performance between males and females. Males scored higher on the SRAVEN's total number correct (M $=45.05, \mathrm{SD}=8.8)$ versus the females $(\mathrm{M}=42.24$, $\mathrm{SD}=9.9)$ resulting in $\mathrm{t}(592)=2.595, \mathrm{p}=0.01$ with a mean difference of 2.816, which represents a large effect size of 5.3. Due to the unequal gender distribution, a Mann-Whitney $U$ test was conducted to investigate any potential differences in the findings as inequality of variances may result in effects on significance levels and the probability of incurring Type I errors. The results mirrored those found on the t-test with the aforementioned tasks yielding $z$ scores of more than 2.5 standard deviations. Based on these findings it appears that gender was significant in mediating performance on these tasks.

\section{Socio-demographic Influences}

In order to assess the degree to which home language, quality of schooling, language of schooling and paternal education influenced performance on the SRAVEN, tests of significance were conducted. Tables 3 through 9 show results of analysis of variance and t-tests which are used to investigate differences on performance on the SRAVEN based on the above-mentioned groupings. The ANOVA results are followed by Bonferroni post-hoc analyzes to locate the differences between groups. All four socio-demographic variables were significantly related to SRAVEN scores. Post-hoc analyzes revealed that black language speakers performed significantly different on the SRAVEN evidencing lower scores.

All language groups were significantly different from one another in terms of language spoken during primary school, as indicated in Table 6, as well as language spoken during high school, as indicated in Table 8 . Individuals who received primary schooling in a black language performed lower than either the English and Afrikaans groups. Individuals schooled in Afrikaans during primary and high school scored significantly higher than either English schooled individuals or black language schooled individuals. Individuals whose fathers completed high school scored significantly higher on the SRAVEN than individuals whose fathers had not completed high school as indicated in Table 9.

There was a significant difference between students who received private education and state funded primary and high schooling on the SRAVEN performance (see Tables 10 and 11. Individuals attending privately funded primary schools obtained significantly higher SRAVEN scores $(t(592)=2.155, p=0.032)$ as did those who received privately funded high schooling $(t(592)=1.971, p=0.049)$.

\section{Interaction Effects}

In order to determine if interaction effects were present, the performance on the SRAVEN was analyzed with a general linear univariate model (see Table 12) with paternal education and quality of education (in both primary and high school) entered as independent variables. There were no significant interaction effects among the variables therefore requiring no further analyzes. Gender differences were not investigated as the skewed sample size would make for caution-bearing interpretation. However, there were differences on the SRAVEN's performance associated with these above-mentioned variables. Table 13 highlights the results.

Of note, individuals whose father had either completed high school and/or furthered his education, generally scored higher than those whose fathers did not complete high school. Also, individuals who received private schooling during primary and high school generally outperformed students who underwent schooling in state funded schools. The highest performers tended to have fathers who had completed high school and gone on to further studies, and who had received private schooling during their primary and high school years. The lowest performers on the SRAVENS tended to have fathers who had not completed high school and who had received state funded schooling during their primary and high school years. The mean SRAVENS score achieved for the former group was $44.17(S D=9.8)$ in comparison to the latter whose mean was 


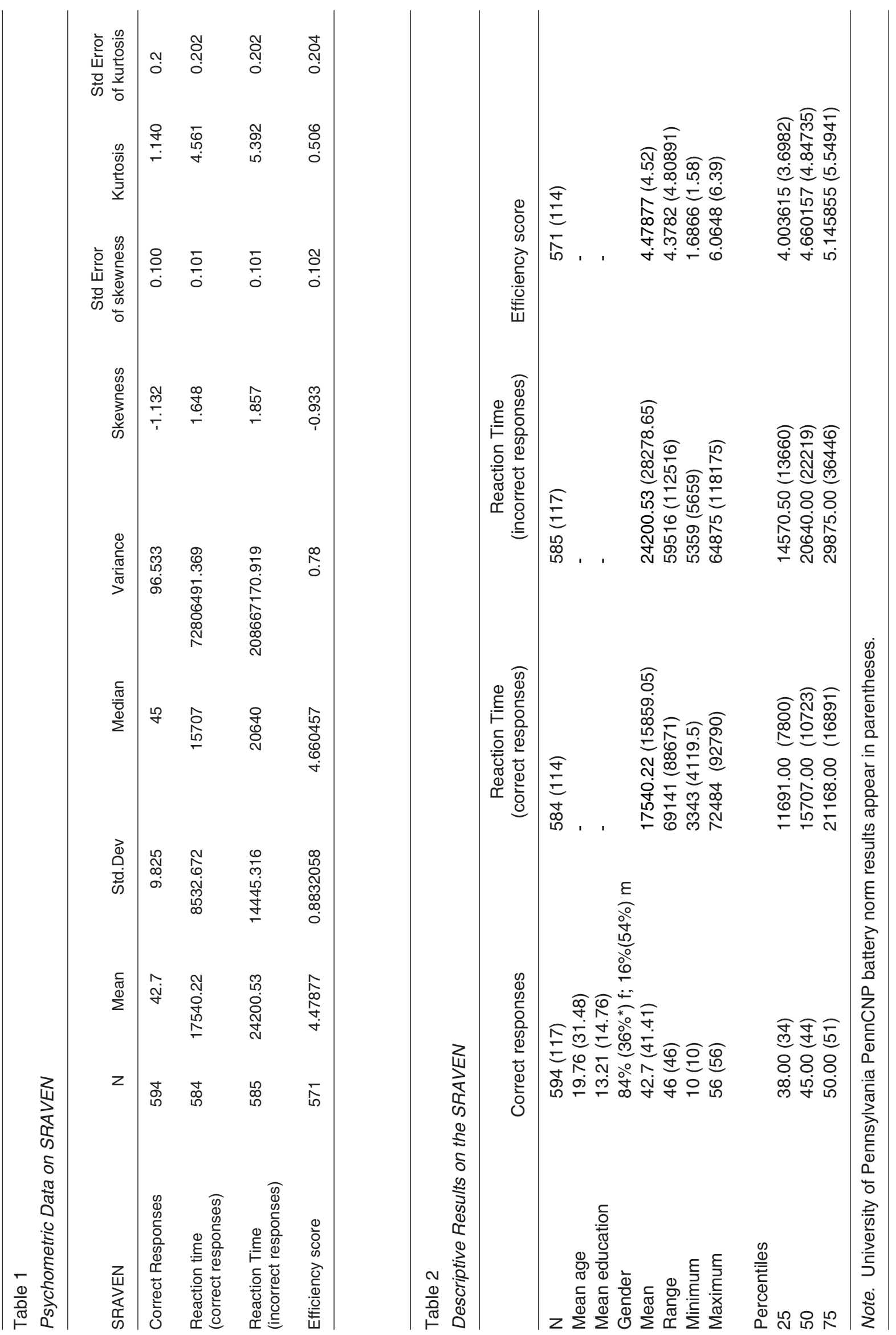


Table 3

Analysis of Variance for Home Language Group on SRAVEN

\begin{tabular}{lrrrr}
\hline & Sum of Squares & df & Mean Square & F \\
\hline Between Groups & 7306.970 & 2 & 3653.485 & 43.239 \\
Within Groups & 49936.877 & 591 & 84.496 & \\
Total & 57243.847 & 593 & & \\
\hline
\end{tabular}

Note. English, Afrikaans and Indigenous home language groups

Table 4

Bonferroni Post-hoc Comparisons Between Home Language Groups on SRAVEN

\begin{tabular}{|c|c|c|c|c|c|c|}
\hline \multirow[b]{2}{*}{ (I) Language } & \multirow[b]{2}{*}{ (J) Language } & \multirow{2}{*}{$\begin{array}{c}\text { Mean } \\
\text { Difference (I-J) }\end{array}$} & \multirow[b]{2}{*}{ Std. Error } & \multirow[b]{2}{*}{ Sig. } & \multicolumn{2}{|c|}{ 95\% Confidence Interval } \\
\hline & & & & & Lower Bound & Upper Bound \\
\hline \multirow[t]{2}{*}{ English } & Afr & -.176 & .903 & 1.000 & -2.34 & 1.99 \\
\hline & Ind & $7.996\left(^{\star}\right)$ & 1.042 & .000 & 5.49 & 10.50 \\
\hline \multirow[t]{2}{*}{ Afrikaans } & Eng & .176 & .903 & 1.000 & -1.99 & 2.34 \\
\hline & Ind & $8.172\left(^{*}\right)$ & .933 & .000 & 5.93 & 10.41 \\
\hline \multirow[t]{2}{*}{ Indigenous } & Eng & $-7.996\left(^{*}\right)$ & 1.042 & .000 & -10.50 & -5.49 \\
\hline & Afr & $-8.172\left(^{\star}\right)$ & .933 & .000 & -10.41 & -5.93 \\
\hline
\end{tabular}

Note. English, Afrikaans and Indigenous Home Language Groups; *The mean difference is significant at the .05 level.

Table 5

Analysis of Variance for Primary School Language on SRAVEN English, Afrikaans and Indigenous Primary School Language Groups

\begin{tabular}{|c|c|c|c|c|c|}
\hline & Sum of Squares & df & Mean Square & $\mathrm{F}$ & Sig. \\
\hline Between Groups & 3532.962 & 2 & 1766.481 & 19.437 & .000 \\
\hline Within Groups & 53710.885 & 591 & 90.881 & & \\
\hline Total & 57243.847 & 593 & & & \\
\hline
\end{tabular}

Note. English, Afrikaans and Indigenous Primary School Language Groups

Table 6

Bonferroni Post-hoc Comparisons Between Primary School Language Groups on SRAVEN

\begin{tabular}{|c|c|c|c|c|c|c|}
\hline \multirow{2}{*}{$\begin{array}{l}\text { (I) Primary } \\
\text { school } \\
\text { language }\end{array}$} & \multirow{2}{*}{$\begin{array}{l}\text { (J) Primary } \\
\text { school } \\
\text { language }\end{array}$} & \multirow{2}{*}{$\begin{array}{c}\text { Mean } \\
\text { Difference (I-J) }\end{array}$} & \multirow[b]{2}{*}{ Std. Error } & \multirow[b]{2}{*}{ Sig. } & \multicolumn{2}{|c|}{$95 \%$ Confidence Interval } \\
\hline & & & & & Lower Bound & Upper Bound \\
\hline \multirow[t]{2}{*}{ English } & Afr & $-2.983\left(^{\star}\right)$ & .831 & .001 & -4.98 & -.99 \\
\hline & Ind & $4.824\left(^{*}\right)$ & 1.303 & .001 & 1.70 & 7.95 \\
\hline \multirow[t]{2}{*}{ Afrikaans } & Eng & $2.983\left(^{*}\right)$ & .831 & .001 & .99 & 4.98 \\
\hline & Ind & $7.807\left(^{*}\right)$ & 1.306 & .000 & 4.67 & 10.94 \\
\hline \multirow[t]{2}{*}{ Indigenous } & Eng & $-4.824\left(^{*}\right)$ & 1.303 & .001 & -7.95 & -1.70 \\
\hline & Afr & $-7.807\left(^{*}\right)$ & 1.306 & .000 & -10.94 & -4.67 \\
\hline
\end{tabular}

Note. English, Afrikaans and Indigenous Primary School Language Groups; * The mean difference is significant at the .05 level. 
Table 7

Analysis of Variance for High School Language on SRAVEN

\begin{tabular}{lrrrr}
\hline & Sum of Squares & df & Mean Square & F \\
\hline Between Groups & 2097.903 & 2 & 1048.952 & 11.242 \\
Within Groups & 55145.944 & 591 & 93.310 & \\
Total & 57243.847 & 593 & & \\
\hline
\end{tabular}

Note.English, Afrikaans and Indigenous High School Language Groups

\section{Table 8}

Bonferroni Post-hoc Comparisons Between High School Language Groups on SRAVEN

\begin{tabular}{|c|c|c|c|c|c|c|}
\hline \multirow{2}{*}{$\begin{array}{l}\text { (I) High school } \\
\text { language }\end{array}$} & \multirow{2}{*}{$\begin{array}{l}\text { (J) High school } \\
\text { language }\end{array}$} & \multirow{2}{*}{$\begin{array}{c}\text { Mean } \\
\text { Difference (I-J) }\end{array}$} & \multirow[b]{2}{*}{ Std. Error } & \multirow[b]{2}{*}{ Sig. } & \multicolumn{2}{|c|}{$95 \%$ Confidence Interval } \\
\hline & & & & & Lower Bound & Upper Bound \\
\hline \multirow[t]{2}{*}{ English } & Afr & $-3.612\left(^{\star}\right)$ & .818 & .000 & -5.58 & -1.65 \\
\hline & Ind & 1.452 & 1.820 & 1.000 & -2.92 & 5.82 \\
\hline \multirow[t]{2}{*}{ Afrikaans } & Eng & $3.612\left(^{\star}\right)$ & .818 & .000 & 1.65 & 5.58 \\
\hline & Ind & $5.064\left(^{*}\right)$ & 1.838 & .018 & .65 & 9.48 \\
\hline \multirow[t]{2}{*}{ Indigenous } & Eng & -1.452 & 1.820 & 1.000 & -5.82 & 2.92 \\
\hline & Afr & $-5.064\left(^{\star}\right)$ & 1.838 & .018 & -9.48 & -.65 \\
\hline
\end{tabular}

Note. English, Afrikaans and Indigenous high school language groups; ${ }^{*}$ The mean difference is significant at the .05 level.

Table 9

Analysis of Variance for Paternal Education on SRAVEN

\begin{tabular}{|c|c|c|c|c|c|}
\hline & Sum of Squares & $d f$ & Mean Square & $F$ & Sig. \\
\hline Between Groups & 1623.317 & 1 & 1623.317 & 17.278 & .000 \\
\hline Within Groups & 55620.530 & 592 & 93.954 & & \\
\hline Total & 57243.847 & 593 & & & \\
\hline
\end{tabular}

Note. Fathers who completed high school and fathers who did not complete high school.

Table 10

Independent Groups t-test for Equality of Means in Primary School Groups on the SRAVEN

\begin{tabular}{|c|c|c|c|c|c|c|c|}
\hline & \multirow[b]{2}{*}{$t$} & \multirow[b]{2}{*}{$d f$} & \multirow{2}{*}{$\begin{array}{l}\text { Sig. } \\
\text { (2-tailed) }\end{array}$} & \multirow{2}{*}{$\begin{array}{c}\text { Mean } \\
\text { Difference }\end{array}$} & \multirow{2}{*}{$\begin{array}{l}\text { Std. Error } \\
\text { Difference }\end{array}$} & \multicolumn{2}{|c|}{$\begin{array}{l}95 \% \text { Confidence } \\
\text { Interval of the Difference }\end{array}$} \\
\hline & & & & & & Upper & Lower \\
\hline SRAVEN & 2.155 & 592 & .032 & 1.736 & .805 & .154 & 3.318 \\
\hline
\end{tabular}

Note. Primary school either state-funded or privately funded 
$38.64(S D=10.3)$. Differences between the two groups have been highlighted in the tables.

\section{Contribution of Socio-demographic Influences}

In a stepwise multiple regression, the independent socio-demographic variables are entered according to their statistical contribution in explaining the variance in SRAVEN's performance. Language used in primary school did not reach significance nor did quality of education in either primary or high school and was thus not included in the model. The order of entry of the variables evidences their relative importance in the model. In the table of variables entered, paternal education was added to the regression equation in model 2 . The increase in R2 as a result of including this variable was 0.26 which was statistically significant, $F(1,591)=17.457, p<0.001$. Similarly, the increase in $\mathrm{R} 2 \mathrm{as}$ a result of including high school language was 0.23 , which was statistically significant, $F(1,590)=15.838, p<$ 0.001 . The order of importance is therefore home language, paternal education and high school language. The negative Beta figures indicate that SRAVEN's performance increases when home language is either Afrikaans or English but decreases if home language is one of the black languages. The results are shown in Tables 14-16.

\section{Discussion}

Our findings evidence support for the influence of various socio-demographic variables on performance of SRAVEN scores. Those who spoke an indigenous home language fared less well than those whose home language was either English or Afrikaans. The language in which education was received during both primary and high school influenced SRAVEN scores. Lastly, paternal education appreciably influenced SRAVEN scores with more educated fathers influencing their children's SRAVEN scores. Our findings are in accord with recent findings in this area, namely that of Gur et al. (2010) whose findings suggest that higher parental education is associated with better performance across domains within executive functioning, on the same neuropsychological test battery. Furthermore, in a study on Philippine students who had diverse socio-demographic backgrounds, Vista and Grantham (2010) found that parental education had a significant influence on fluid intelligence. Lawlor, Najman, Batty, O'Callaghan, Williams, and Bor (2006) in their study, via multivariable analyses, contend that among the strongest and most robust predictors of intelligence are family income, parental education and education, with these and other variables explaining $7.5 \%$ of the variation in intelligence at age 14. Moreover, Brooks (2010) looked at the prevalence of low intelligence test scores on the WISC-IV and concluded that the frequency base rates of low intelligence scores are related both to a child's level of intelligence and parental education.

Given the generational disparities in parental access to education in South Africa, researchers should be cognizant of the variable effect that parental education levels have on certain do-

Table 11

Independent Groups t-test for Equality of Means in High School Groups on the SRAVEN

\begin{tabular}{cccccccc}
\hline & & & & & \multicolumn{2}{c}{$95 \%$ Confidence } \\
& $\mathrm{t}$ & $\mathrm{df}$ & $\begin{array}{c}\text { Sig. } \\
(2 \text {-tailed })\end{array}$ & $\begin{array}{c}\text { Mean } \\
\text { Difference }\end{array}$ & $\begin{array}{c}\text { Std. Error } \\
\text { Difference }\end{array}$ & \multicolumn{2}{c}{ Interval of the Difference } \\
SRAVEer & 1.971 & 592 & .049 & 1.588 & .806 & .006 & 3.171 \\
\hline
\end{tabular}

Note. High school either state-funded or privately funded.

Table 12

General Linear Univariate Analysis on SRAVEN for two Independent Socio-Demographic Variables

\begin{tabular}{|c|c|c|c|c|c|c|}
\hline Source & $\begin{array}{l}\text { Type III } \\
\text { Sum of } \\
\text { Squares }\end{array}$ & df & $\begin{array}{l}\text { Mean } \\
\text { Square }\end{array}$ & $\mathrm{F}$ & Sig. & $\begin{array}{l}\text { Partial } \\
\text { Eta } \\
\text { Squared }\end{array}$ \\
\hline Model & $1085112.471(a)$ & 8 & 135639.059 & 1447.106 & .000 & .952 \\
\hline Paternal Education & 328.722 & 1 & 328.722 & 3.507 & .062 & .006 \\
\hline Quality of Ed (prim) & 66.726 & 1 & 66.726 & .712 & .399 & .001 \\
\hline Quality of Ed (high) & 44.851 & 1 & 44.851 & .479 & .489 & .001 \\
\hline Paternal Education * Quality of Ed (prim) & 23.491 & 1 & 23.491 & .251 & .617 & .000 \\
\hline Paternal Education * Quality of Ed (high) & 56.881 & 1 & 56.881 & .607 & .436 & .001 \\
\hline Quality of Ed (prim) * Quality of Ed (high) & .984 & 1 & .984 & .010 & .918 & .000 \\
\hline $\begin{array}{l}\text { Paternal Education * Quality of Ed } \\
(\text { prim) })^{*} \text { Quality of Ed (high) }\end{array}$ & 53.731 & 1 & 53.731 & .573 & .449 & .001 \\
\hline Error & 54926.529 & 586 & 93.731 & & & \\
\hline Total & 1140039.000 & 594 & & & & \\
\hline
\end{tabular}

Note. a R Squared $=.952$ (Adjusted R Squared $=.951$ ) 
Table 13

Paternal Education X Quality of Education (primary) X Quality of Education (high)

\begin{tabular}{|c|c|c|c|c|c|c|c|}
\hline \multirow{4}{*}{$\begin{array}{l}\text { Paternal } \\
\text { Ed } \\
\begin{array}{l}\text { Below high } \\
\text { school }\end{array}\end{array}$} & \multirow{2}{*}{$\begin{array}{l}\text { Quality of } \\
\text { Ed (prim) }\end{array}$} & \multirow{2}{*}{\multicolumn{2}{|c|}{$\begin{array}{l}\text { Quality of } \\
\text { Ed (high) }\end{array}$}} & \multirow[t]{2}{*}{ Mean } & \multirow[t]{2}{*}{ Std. Error } & \multicolumn{2}{|c|}{ 95\% Confidence Interval } \\
\hline & & & & & & Lower Bound & Upper Bound \\
\hline & & Private & Private & 42.382 & 1.174 & 40.076 & 44.688 \\
\hline & & & State funded & 41.571 & 3.659 & 34.385 & 48.758 \\
\hline & & State funded & Private & 41.739 & 2.019 & 37.774 & 45.704 \\
\hline & & & State funded & 38.647 & .959 & 36.764 & 40.530 \\
\hline High school & & Private & Private & 44.174 & .714 & 42.772 & 45.576 \\
\hline and above & & & State funded & 43.421 & 2.221 & 39.059 & 47.783 \\
\hline & & State funded & Private & 42.850 & 1.531 & 39.844 & 45.856 \\
\hline & & & State funded & 43.834 & .788 & 42.287 & 45.382 \\
\hline
\end{tabular}

Note. Dependent variable: Correct responses on the Ravens

Table 14

Stepwise Multiple Regression Model Summary

\begin{tabular}{|c|c|c|c|c|c|c|c|c|c|}
\hline Model & $\mathrm{R}$ & R Square & $\begin{array}{l}\text { Adjusted } \\
\text { R Square }\end{array}$ & $\begin{array}{l}\text { Std Error of } \\
\text { the Estimate }\end{array}$ & & Chan & e Stat & & \\
\hline & $\begin{array}{l}\text { R Square } \\
\text { Change }\end{array}$ & F Change & df1 & $\mathrm{df} 2$ & $\begin{array}{l}\text { R Square } \\
\text { Change }\end{array}$ & F Change & $\mathrm{df1}$ & $d f$ & $\begin{array}{l}\text { Sig. F } \\
\text { Change }\end{array}$ \\
\hline 1 & $.287(a)$ & .083 & .081 & 9.418 & .083 & 53.313 & 1 & 592 & .000 \\
\hline 2 & $.330(b)$ & .109 & .106 & 9.290 & .026 & 17.457 & 1 & 591 & .000 \\
\hline 3 & $.364(\mathrm{c})$ & .132 & .128 & 9.176 & .023 & 15.838 & 1 & 590 & .000 \\
\hline
\end{tabular}

Note. ${ }^{a}$ Predictors: (Constant), Home language; ${ }^{b}$ Predictors: (Constant), Home language, Paternal education; ${ }^{\mathrm{C}}$ Predictors: (Constant), Home language, Paternal education, High school language

Table 15

ANOVA for Stepwise Multiple Regression

\begin{tabular}{|c|c|c|c|c|c|c|}
\hline \multicolumn{2}{|c|}{ Model } & \multirow{2}{*}{$\begin{array}{c}\text { Sum of Squares } \\
4729.268\end{array}$} & \multirow{2}{*}{$\frac{d f}{1}$} & \multirow{2}{*}{$\begin{array}{c}\text { Mean Square } \\
4729.268\end{array}$} & \multirow{2}{*}{$\begin{array}{c}F \\
53.313\end{array}$} & \multirow{2}{*}{$\begin{array}{l}\text { Sig. } \\
.000(a)\end{array}$} \\
\hline 1 & Regression & & & & & \\
\hline & Residual & 52514.578 & 592 & 88.707 & & \\
\hline & Total & 57243.847 & 593 & & & \\
\hline \multirow[t]{3}{*}{2} & Regression & 6235.906 & 2 & 3117.953 & 36.126 & $.000(b)$ \\
\hline & Residual & 51007.941 & 591 & 86.308 & & \\
\hline & Total & 57243.847 & 593 & & & \\
\hline \multirow[t]{3}{*}{3} & Regression & 7569.410 & 3 & 2523.137 & 29.968 & $.000(c)$ \\
\hline & Residual & 49674.436 & 590 & 84.194 & & \\
\hline & Total & 57243.847 & 593 & & & \\
\hline
\end{tabular}

Note. ${ }^{a}$ Predictors: (Constant), Home language; ${ }^{b}$ Predictors: (Constant), Home language, Paternal education; ${ }^{c}$ Predictors: (Constant), Home language, Paternal education; High school language; d Dependent Variable: SRAVEN. 
Table 16

Coefficients for Stepwise Multiple Regression

\begin{tabular}{|c|c|c|c|c|c|c|c|c|c|}
\hline \multicolumn{2}{|c|}{ Model } & \multicolumn{2}{|c|}{$\begin{array}{l}\text { Unstandardized } \\
\text { Coefficients }\end{array}$} & \multirow{2}{*}{$\begin{array}{c}\text { Standandized } \\
\text { Coefficients }\end{array}$} & \multirow{2}{*}{$\frac{\mathrm{t}}{\text { Zero-order }}$} & \multicolumn{2}{|l|}{ Sig. } & \multicolumn{2}{|c|}{ Correlations } \\
\hline & & B & Std. Error & & & Partial & Zero-order & Partial & Part \\
\hline \multirow[t]{2}{*}{1} & (Constant) & 50.382 & 1.121 & & 44.925 & .000 & & & \\
\hline & Home language & -3.896 & .534 & -.287 & -7.302 & .000 & -.287 & -.287 & -.287 \\
\hline \multirow[t]{3}{*}{2} & (Constant) & 44.682 & 1.756 & & 25.439 & .000 & & & \\
\hline & Home language & -3.849 & .526 & -.284 & -7.311 & .000 & -.287 & -.288 & -.284 \\
\hline & Paternal Education & 3.371 & .807 & .162 & 4.178 & .000 & .168 & .169 & .162 \\
\hline \multirow[t]{4}{*}{3} & (Constant) & 41.691 & 1.891 & & 22.052 & .000 & & & \\
\hline & Home language & -4.225 & .528 & -.312 & -7.994 & .000 & -.287 & -.313 & -.307 \\
\hline & Paternal Education & 3.254 & .797 & .157 & 4.081 & .000 & .168 & .166 & .157 \\
\hline & $\begin{array}{l}\text { Medium of language } \\
\text { (high school) }\end{array}$ & 2.563 & .644 & .155 & 3.980 & .000 & .105 & .162 & .153 \\
\hline
\end{tabular}

Note. ${ }^{a}$ Dependent Variable: SRAVEN

mains of cognitive functioning. In our findings paternal education was the second-most important predictor of SRAVEN performance as evidenced in the regression results. Socio-demographic variables are found to be salient moderators of potential SRAVEN performance as these variables are repeatedly found to be influential in affecting cognitive domain performance. There is comparatively less research focusing on parental education as opposed to participant level of education as moderating the effect on computerized neuropsychological performance in diverse contexts and our findings add to this research area.

Significant group differences on performance observed in this study are partly attributable to home language, school language and paternal education. The results of this study indicated substantial differences between these groups adding further support to the findings in the literature, cf. Braga, 2007; Hoff, 2003; Noble et al., 2005. As with the Lynn et al. (2005) Raven's research, our study evidenced similar findings but with paternal education as opposed to maternal education as being more important and significant a contribution to performance on the test. Further investigations into interactions did not yield significant findings but this may be due to a restricted sample range. Our study also added support to the idea that inherent disadvantages exist within certain community groupings in South Africa due to impoverished environments (Grieve \& Viljoen, 2000; Nell, 2000).

Our study found significant differences in Raven's performance between the different groups when accounting for home language, quality of schooling, language of schooling and paternal education. Individuals whose parents were better educated and who received instruction in English performed significantly better than those whose parents were less educated in addition to receiving school instruction in a language other than English or Afrikaans. The quality of education received during primary and high school played a significant role in differentiating individuals on Raven's performance. Our findings further underscore the complex relationship between socio-demographic factors and measures of intelligence. The association between socio-demographic factors and Raven's performance is determined by the broader context. This context includes varying degrees of accessibility to quality schooling in South Africa. Language and parental education issues are significantly tied into neuropsychological performance thus illustrating the deleterious effects of sub-optimal education. The net result is lowered performance on non-verbal tests which are supposedly advocated as being independent of such factors. These findings provide the impetus for future researchers in South Africa to consider the stratification of the sociodemograhic variables of interest. Quality of eduation, for example, is a complex construct/concept that has a myriad of sociocontextual (urban-rural) related factors.

\section{Limitations}

The sample utilized for this study was one of convenience and as such performance indicators will reflect a restriction of range. Hence, the results are thus not generalizable. The sample stratification can be considered a limitation of this research endeavor as it may not be optimal in terms of teasing apart very difficult aspects surrounding quality of education in South Africa. Biological underpinnings of cognitive functioning are not addressed in the research and as such the discussion may not reflect the current debates within the field. Due to the rapid rate of adaptation of black South Africans to neuropsychological tests, what may have appeared to have been significant findings in the early 1990's may no longer be the case today.

\section{Conclusion}

Research indicates that non-verbal neuropsychological tests are significantly influenced by a variety of socio-demographic factors. Language proficiency and language ability have been shown to significantly impact on and moderate neuropsychological performance. In addition to language fluency, parental education has also been cited as playing a significant role in test performance. South Africa presents as a natural experiment regarding the study of various socio-demographic influences where, due to inequities of the past, differences between group performance based on the former variables are evident.

\section{References}

Ardila, A., \& Keating, K. (2007). Cognitive abilities in different cultural contexts. In B. Uzzell, M. Ponton, \& A. Ardila (Eds.), 
International handbook of cross-cultural neuropsychology (pp. 109-125). London, England: Lawrence Erlbaum.

Ardila, A., Rosselli, M., Matute, E., \& Guajardo, S. (2005). The influence of parents' educational level on the development of executive functions. Developmental Neuropsychology, $28,539-560$.

Braga, L. W. (2007). Developmental perspectives: Culture and neuropsychological development during childhood. In B. Uzzell, M. Ponton, \& A. Ardila (Eds.), International handbook of cross-cultural neuropsychology (pp. 145-161). London, England: Lawrence Erlbaum.

Brooks, B. L. (2010). Seeing the forest for the trees: Prevalence of low scores on the Wechsler Intelligence Scale for Children (WISC-IV) (4th ed.) Psychological Assessment, 22(3), 650-656.

Coffey, D. M., Marmol, L., Schock, L., \& Adams, W. (2005). The influence of acculturation on the Wisconsin Card Sorting Test by Mexican Americans. Archives of Clinical Neuropsychology, 20, 795-803.

Dotson, V. M., Kitner-Triolo, M., Evans, M. K., \& Zonderman, A. B. (2008). Literacy-based normative data for low socioeconomic status African Americans. The Clinical Neuropsychologist, 22, 989-1017.

Dugbartey, A.T., Townes, B., \& Mahurin, R. (2000). Equivalence of the Color Trails Test and Trail Making Test in non-native English-speakers. Archives of Clinical Neuropsychology, 15(5), 425-431.

Griesel, R. D., \& Richter, L. M. (1987). Psycho-social studies of malnutrition in southern Africa. World Review of Nutrition and Dietetics, 54, 71-104.

Grieve, K. W., \& Viljoen, S. (2000). An exploratory study of the use of the Austin Maze in South Africa. South African Journal of Psychology, 30, 14-18.

Gur, R., Ragland, J., Moberg, P. J., Turner, T. H., Bilker, W. B., Kohler, C., . . \& \& Gur, R. E. (2001). Computerized neurocognitive scanning: Methodology and validation in healthy people. Neuropsychopharmacology, 25, 766-776.

Gur, R. C., Richard, J., Hughett, P., Calkins, M. E., Macy, L., Bilker, W. B., . . \& \& Gur. R. E. (2010). A cognitive neuroscience-based computerized battery for efficient measurement of individual differences: Standardization and initial construct validation. Journal of Neuroscience Methods, 187, 254-262.

Hoff, E. (2003). The specificity of environmental influence: Socioeconomic status affects early development via maternal speech. Child Development, 74, 1368-1378.

Knoetze, J., Bass, N., \& Steele, G. (2005). The Raven's Coloured Progressive Matrices: Pilot norms for isiXhosa-speaking primary school learners in peri-urban Eastern Cape. South African Journal of Psychology, 35(2), 175-194.

Lawlor, D. A., Najman, J. M., Batty, G. D., O'Callaghan, M. J., Williams, G. M., \& Bor, W. (2006). Early life predictors of childhood intelligence: Findings from the Mater-University study of pregnancy and its outcomes. Paediatric and Perinatal Epidemiology, 20, 148-162.

Lynn, R., Backhoff, E., \& Contreras, L.A. (2005). Ethnic and racial differences on the Standard Progressive Matrices in Mexico. Journal of Biosocial Science, 37, 107-113.

Maree, K., Aldous, C., Hatting, A., Swanepoel, A., \& van der Linde, M. (2006). Predictor of learner performance in mathematics and science according to a large-scale study in
Mpumalanga. South African Journal of Education, 22(2), 229-252.

Mok, N., Tsang, L., Lee, T. M., \& Llorente, A. M. (2008). The impact of language on the equivalence of trail making tests: Findings from three pediatric cohorts with different language dominance. Applied Neuropsychology, 15, 123-130.

Nell, V. (2000). Cross-cultural neuropsychological assessment: Theory and practice. London, England: Lawrence Erlbaum.

Nelson, N. W., \& Pontón, M. (2007). The art of clinical neuropsychology. In B. Uzzell, M. Ponton, \& A. Ardila (Eds.), International Handbook of cross-cultural neuropsychology (pp. 45-62). London, England: Lawrence Erlbaum.

Noble, K. G., Norman, M. F., \& Farah, M. J. (2005). Neurocognitive correlates of socioeconomic status in kindergarten children. Developmental Science, 8(1), 74-87.

Noble, K. G., McCandliss, B. D., \& Farah, M. J. (2007). Socioeconomic gradients predict individual differences in neurocognitive abilities. Developmental Science, 10(4), 464-480.

Owen, K. (1992). The suitability of the Raven's standard progressive matrices for various groups in South Africa. Personality and Individual Differences, 13, 149-159.

Raven, J. C., Court, J. H., \& Raven, J. C. (1990). Manual for raven's progressive matrices and vocabulary scales - Section 2: Coloured progressive matrices. Oxford, United Kingdom: Oxford Psychologists Press.

Raven, J., Raven, J.C., \& Court, J.H. (2000). Manual for raven's standard progressive matrices. San Antonio, TX: Harcourt.

Razani, J., Burciaga, J., Madore, M., \& Wong, J. (2007). Effects of acculturation on tests of attention and information processing in an ethnically diverse group. Archives of Clinical Neuropsychology, 22, 333-341.

Rosselli, M., \& Ardila, A. (2003). The impact of culture and education on non-verbal neuropsychological measurements: A critical review. Brain and Cognition, 52, 326-333.

Rushton, J. P., \& Skuy, M. (2000). Performance on Raven's Matrices by African and White university students in South Africa. Intelligence, 28(4), 251-265.

Rushton, J. P., Skuy, M., \& Fridjhon, P. (2002). Jensen effects among African, Indian, and White engineering students in South Africa on Raven's Standard Progressive Matrices. Intelligence, 30, 409-423.

Sherwood, A. R. (2005). Neuropsychological test performance among Navajo native Americans: A normative sample. Dissertation Abstracts International: Section B: The Sciences and Engineering, 65(9-B), 4864.

Shuttleworth-Edwards, A., Donnelly, M., Reid, I., \& Radloff, S. (2004a). A cross-cultural study with cultural fair normative indications on the WAIS-III Digit Symbol - Incidental Learning. Journal of Clinical and Experimental Neuropsychology, 26(7), 921-932.

Shuttleworth-Edwards, A., Kemp, R., Rust, A., Muirhead, J., Hartman, N., \& Radloff, S. (2004b). Cross-cultural effects on $I Q$ test performance: A review and preliminary normative indications on WAIS-III test performance. Journal of Clinical and Experimental Neuropsychology, 26(7), 903-920.

Shuttleworth-Jordan, A. B. (1996). On not reinventing the wheel: A clinical perspective on culturally relevant test usage in South Africa. South African Journal of Psychology, 26(2), 96-102. 
Sugarman, R. (2002). Evolution and executive functions: Why our toolboxes are empty. Revista Española de Neuropsicologia, 4, 351-377.

Sugarman, R. (2007). Visuospatial assessment in cross-cultural and non-western settings. In B. Uzzell, M. Ponton, \& A. Ardila (Eds.), International handbook of cross-cultural neuropsychology (pp. 227-251). London, England: Lawrence Erlbaum.

Vista, A. D., \& Grantham, T. C (2010). Effects of parental education levels on fluid intelligence of Philippine public school students. Journal of Psychoeducational Assessment, 28(3), 236-248.

\section{Author Note}

This work was supported by a grant from the South African National Research Foundation and the University of Pretoria Research and Development Programme. 
